OPEN ACCESS

Edited by:

Zikria Saleem,

University of Lahore, Pakistan

Reviewed by:

Suela Kellici,

University of Medicine, Tirana, Albania

Tauqeer Hussain Mallhi,

Al Jouf University, Saudi Arabia Inayat Ur Rehman,

Monash University Malaysia, Malaysia

*Correspondence:

Raja Ahsan Aftab

rajaahsan.aftab@taylors.edu.my

Specialty section:

This article was submitted to

Drugs Outcomes

Research and Policies,

a section of the journal

Frontiers in Pharmacology

Received: 10 May 2021

Accepted: 27 July 2021

Published: 10 August 2021

Citation:

Abbasi SH, Aftab RA, Lai PSM, Lim SK and Zainol Abidin RN (2021) Impact of Healthcare Associated Infections on Survival and Treatment Outcomes Among End Stage Renal Disease Patients on Renal

Replacement Therapy.

Front. Pharmacol. 12:707511. doi: 10.3389/fphar.2021.707511

\section{Impact of Healthcare Associated Infections on Survival and Treatment Outcomes Among End Stage Renal Disease Patients on Renal Replacement Therapy}

\author{
Saad Hanif Abbasi ${ }^{1}$, Raja Ahsan Aftab ${ }^{1 *}$, Pauline Siew Mei Lai ${ }^{2}$, Soo Kun Lim $^{3}$ and \\ Ruwaida Nur Zainol Abidin ${ }^{4}$
}

${ }^{1}$ School of Pharmacy, Taylor's University, Subang Jaya, Malaysia, ${ }^{2}$ Department of Primary Care Medicine, Faculty of Medicine, University of Malaya, Kuala Lumpur, Malaysia, ${ }^{3}$ Department of Medicine (Division of Nephrology), Faculty of Medicine, University of Malaya, Kuala Lumpur, Malaysia, ${ }^{4}$ Department of Pharmacy, Hospital Serdang, Kajang, Malaysia

Background: Due to frequent hospitalizations, complex dialysis procedures and immune compromising effects of end stage renal disease (ESRD), patients on dialysis are more prone to healthcare associated infections (HCAls).

Objective: To study the impact of HCAls on survival and treatment outcomes among ESRD patients on renal replacement therapy (RRT).

Methodology: A multicenter, retrospective study was conducted from June to December 2019 at two public hospitals of Malaysia. ESRD patients with minimum of 6 months on RRT were included, while pregnant patients and patients $<18$ years were excluded. Multinomial logistic regression was performed to identify risk factors associated with unsuccessful treatment outcomes. Kaplan Meier analysis was performed to study the survival.

Results: A total of 670 records were examined, of which 400 patients were included as per the inclusion criteria. The mean survival time of patients without HCAls [22.7 (95\% Cl: 22.1-23.2)] was higher than the patients with HCAls [19.9 (95\%Cl:18.8-20.9)]. Poor survival was seen in patients with $>2$ comorbidities, $>60$ years of age, low hemoglobin concentration and high C-reactive protein levels. The most frequent treatment outcome was cured [113 (64.9\%)], followed by death [37 (21.3\%)] and treatment failure [17 (9.8\%)]. Advancing age, and low hemoglobin concentration were independent risk factors associated with death, while recurrent HCAls, use of central venous catheters, and low serum sodium levels were risk factors for treatment failure.

Conclusion: The high burden of HCAls is a profound challenge faced by patients on RRT, which not only effects the treatment outcomes but also contributes substantially to the poor survival among these patients.

Keywords: healthcare associated infections, end stage renal disease (ESRD), renal replacement therapy (RRT), peritoneal dialysis (PD), hemodialysis (HD), treatment outcome 


\section{INTRODUCTION}

According to an estimate, the global prevalence of end stage renal disease (ESRD) patients undergoing maintenance hemodialysis is increased by 1.7 times from 1990 to 2010 (Thomas et al., 2015). Due to frequent hospitalizations, complex dialysis procedures and immune compromising effects of ESRD, patients on dialysis are more prone to healthcare associated infections (HCAIs) (Donlon et al., 2011; Albuquerque et al., 2014). Moreover, HCAIs are among the major causes of increased morbidity and mortality among these patients (Gupta et al., 2013). According to the United States renal data system, sepsis mortality was 100-300 times higher for chronic dialysis patients compared to general public (Sarnak and Jaber, 2000). Furthermore, almost $20 \%$ of patients on renal replacement therapy (RRT) had at least one episode of septicemia (Sarnak and Jaber, 2000). The recent report of Malaysian dialysis and transplant registry report (Ghazali et al., 2016) suggested that sepsis accounts for $28 \%$ of all causes of deaths among patients on dialysis (Ghazali et al., 2016).

Antibiotic treatment failure, which is one of the representatives of antibiotic resistance is increased alarmingly over the past few decades and World Health Organization has declared this a global public health crisis (World Health Organization, 2012). It is still unclear whether the differences in mortality and treatment outcomes among dialysis patients result from differences in patient- and facility related factors, inappropriate, suboptimal, or delayed antibiotic therapy, various complications and comorbid conditions, or other factors. There is a need to better characterize and understand the epidemiology and impact of HCAIs on antibiotic treatment outcomes and patients' survival, which is not simple owing to different infection types, pathogens' characteristics and large number of antibiotic treatment options available. Only limited information is available on the factors that contribute to poor clinical outcomes and survival among the high risk ESRD population. The present study was performed to determine the impact of HCAIs on treatment outcomes and survival among ESRD patients on RRT.

\section{METHODOLOGY}

\section{Study Setting and Study Design}

A multicenter, cross sectional, retrospective study was conducted at two study sites in Malaysia, including the University Malaya Medical Centre, and Serdang Hospital. UMMC is a tertiary hospital, located in Kuala Lumpur, Malaysia. The UMMC services over 900 inpatients and approximately 1,500 outpatients daily. On average, 80-90 patients undergo hemodialysis (HD) in this hospital. Hospital Serdang is a tertiary hospital situated in the Sepang District in Selangor. It has $100 \mathrm{HD}$ patients and more than 300 patients on peritoneal dialysis (PD). Both hospitals are government funded.

\section{Patient Population}

ESRD patients who were on either HD or PD for a minimum period of 6 months were included, while patients who were pregnant, $<18$ years and those who have undergone kidney transplantation were excluded. Data of patients who were diagnosed with ESRD (defined as those classified with the international classification of diseases (ICD)-10-CM code N18.6 for ESRD (Wang and Hoy, 2013)) from 2015 to 2019 were extracted from the hospital's medical records computerized system. All patients were then screened to see if they fit the study's inclusion/exclusion criteria. The medical records and laboratory data were reviewed using the hospital's total hospital information system (THIS) to confirm the diagnosis of any HCAI. All data were collected from the time of initiation of dialysis for each patient till 2019. A data collection form was used to retrieve patient demographics and clinical information.

The sample size required was 400 case records (with $80 \%$ power and $95 \%$ confidence interval (Raosoft. Sample size calc, 2004). To reduce the risk of selection bias, a simple random sampling technique-a research randomizer (Research Randomizer, 1997) was used. Research randomizer utilizes the total number of patients and the sample size to generate random numbers. Each number was noted, and the patient associated with that number on the list was selected.

\section{Criteria for the Selection of Healthcare Associated Infections}

For the purpose of this study, the modified definition from Friedman et al. (2002) was adopted as the initial definition of HCAIs (Friedman et al., 2002), where HCAI is defined as "an infection present at the time of hospital admission or within $48 \mathrm{~h}$ of admission, resulting from medical care or treatment in a hospital, primary healthcare setting, nursing home, or patient's home". An infection was said to be healthcare associated, if the patient had fulfilled any of the following criteria (Friedman et al., 2002), including 1)received any intravenous therapy, wound care or specialized nursing care at home or through a healthcare agency or had self-administered intravenous therapy in 30 days before the infection, 2)had a hospital visit or received intravenous chemotherapy in the previous 30 days or 3)was hospitalized in an acute care hospital for 2 or more days in the previous 90 days.

Following definitions of treatment outcomes were used in the study (Zelenitsky et al., 2003; Wen et al., 2018; Cilli et al., 2018):

Clinical cure (successful treatment outcome) was defined as resolution of clinical signs and symptoms within 30 days of infection or have negative blood culture after completion of therapy. Death (unsuccessful treatment outcome) was defined as mortality due to any cause during treatment within 2 days (early mortality) or within 2-30 days (late mortality) of a positive blood culture. Treatment failure (unsuccessful treatment outcome) indicated persistent infection or unimproved patient's clinical status and the need to switch to another antibiotic regimen after 3 days of initial treatment. Finally, defaulted or transferred out patients were those whose treatments were interrupted for any reason or those who were 
transferred to another healthcare facility before completion of the therapy.

\section{Study Endpoints}

The primary endpoint of the study was the 24 months survival (Etikan et al., 2017) of patients from November 2017 till the completion of medical records viewing, whereas the secondary endpoint was mortality due to any cause during this period. All transferred patients and those who could not be followed up through record viewing were tracked using their contact numbers to get their final status. Any patient with an unidentified final status was not included in the survival analysis. Patients were divided during survival analysis as complete follow-up (alive), primary end point reached (alive), death (dead), transferred out (alive/dead).

\section{Ethical Considerations}

Ethical approval was obtained from the University Malaya Medical Research Ethics Committee (MREC ID NO: 2019320-7245) and the National Malaysian Research Registry (NMRR-19-777-47089) before the initiation of study.

\section{Statistical Analysis}

Data were coded into nominal, ordinal and continuous variables using the Statistical Package for Social Sciences version 20.0 (SPSS Inc., Chicago, IL, United States). Kolmogorov-Smirnov test was used to assess the normality of data. Both descriptive and inferential statistics were applied to achieve the study objectives. A descriptive analysis of patients' data was conducted to examine the variables of interest. All categorical variables were presented as absolute frequencies and percentages, while median and interquartile range were used to present continuous variables as normality could not be assumed. Both Chi-square and Fischer's exact test were used to assess all associations involving categorical variables. These significantly associated variables were included in regression analysis. As the dependent variable was of categorical type with more than two levels, multinomial logistic regression was used to analyze the relationship between independent variables and unsuccessful treatment outcomes. Both univariate and multivariate multinomial logistic regression were used to identify independent risk factors associated with unsuccessful treatment outcomes. Presence and absence of HCAIs were analyzed against the patient's status using Kaplan Meier analysis to study the survival among two patient groups (with and without HCAIs). A $p$-value of $<0.05$ was considered to be statistically significant.

\section{RESULTS}

Out of 670 patient records identified during database search, 400 patients were included as that fitted the inclusion criteria. Fifty seven out of 400 patients were defaulted or transferred out and their final status was unknown, hence they were excluded from survival analysis. Of the remaining 343 participants, there were $142(41.3 \%)$ and $201(58.7 \%)$ patients with and without HCAIs, respectively. There were significantly a greater number of deaths [53(37.3\%)] in the group of patients with HCAIs, compared to
$22(10.9 \%)$ deaths in the group without HCAIs ( $p$-value $<0.001)$. Baseline characteristics of participants in both the groups are shown in Table 1.

The total number of deaths during the 24 months follow-up period was $\mathrm{n}=53(37.3 \%)$ for patients' group with HCAIs and $n=$ $22(10.9 \%)$ for the group without HCAIs. The mean survival time of patients in the group without HCAIs [22.7(95\%CI:22.1-23.2)] was higher than the group with HCAIs [19.9(95\%CI:18.8-20.9)] and was found to be statistically significant ( $p$-value $<0.001$; Figure 1). During the study, a significantly better survival $(p$-value $=0.001)$ was observed among patients aged 18-40 years [22.8(95\%CI:21.7-23.9)] and 41-60 years [22.5(95\%CI:21.7-23.3)] as compared to patients aged $>60$ years [20.7 (95\%CI:19.8-21.5)]. Survival trends of study population are shown in Table 2.

Cox regression was applied for predictors associated with survival among study population. Group of patients with HCAIs (HR 1.4) had poor survival and 1.4-folds increased chances of death than group of patients without HCAIs, but the result was statistically nonsignificant $(p=0.288)$. Moreover, poor survival was seen among patients with $>2$ comorbidities, $>60$ years of age, Low $\mathrm{Hb}$ concentration and high CRP levels during 24-months survival analysis. However, during multivariate regression analysis, factors such as more than 2 comorbidities, above 60 years of age, low hemoglobin levels and high C-reactive protein concentration were not found to be significantly associated with survival among ESRD patients with or without HCAIs (Table 3).

\section{Treatment Outcomes}

There were $174(43.5 \%)$ patients with at least one episode of HCAI. The most prevalent HCAI was catheter related bloodstream infection (CRBSI) [64 (36.8\%)], while peritonitis [45 (25.8\%)] and pneumonia [37 (21.2\%)] were also very common. The most frequent treatment outcome seen in this study was cured [113 (64.9\%)], followed by death [37 (21.3\%)] and treatment failure 17 (9.8\%). Moreover, there were 66 (37.9\%) patients with recurrent HCAIs. Clinical and sociodemographic variables, such as age, type of dialysis, recurrent HCAIs, type of vascular access, occurrence of CRBSI, sodium and hemoglobin levels were significantly associated with these treatment outcomes (Table 4).

In univariate multinomial logistic regression, factors such as advancing age $(\mathrm{OR}=1.06 ; 95 \% \mathrm{CI}: 1.02-1.1, p$-value $=0.001)$, low serum sodium levels $(\mathrm{OR}=2 ; 95 \% \mathrm{CI}: 0.9-4.3, p$-value $=$ $0.059)$ and low blood hemoglobin concentration $(\mathrm{OR}=6.8$; 95\%CI:0.8-52, $p$-value $=0.066$ ) were significantly associated with higher number of deaths from HCAIs. However, recurrent HCAIs $(\mathrm{OR}=37 ; 95 \% \mathrm{CI}: 4.7-291, p$-value $=$ 0.001 ), occurrence of CRBSI (OR $=5.9 ; 95 \% \mathrm{CI}: 1.8-19.4$, $p$-value $\leq 0.003)$, use of CVCs $(\mathrm{OR}=8.8 ; 95 \% \mathrm{CI}: 2.8-27$, $p$-value $<0.001)$, and low serum sodium levels $(\mathrm{OR}=4.2$; 95\%CI:1.3-12.8, $p$-value $=0.011$ ) were more likely to cause treatment failure in patients with HCAIs. During multivariate multinomial logistic regression, advancing age $(\mathrm{OR}=1.06$; 95\%CI:1.02-1.1, $p$-value $=0.001)$, and low blood hemoglobin concentration $(\mathrm{OR}=9.1 ; 95 \% \mathrm{CI}: 1.1-86, p$-value $=0.039)$ were 
TABLE 1 | Matching criteria for survival analysis: Baseline characteristics of interest in patients with and without healthcare associated infections

\begin{tabular}{|c|c|c|c|c|}
\hline & $\begin{array}{l}\text { Total no. of } \\
\text { ESRD patients on } \\
\text { RRT }(\mathrm{N}=400)\end{array}$ & $\begin{array}{l}\text { Patients with HCAls } \\
\qquad(n=142)\end{array}$ & $\begin{array}{l}\text { Patients without HCAls } \\
\qquad(n=201)\end{array}$ & $p$-value ${ }^{a}$ \\
\hline Median age in years (IQR) & $62(18)$ & $61.5(17)$ & $61(20)$ & 0.001 \\
\hline Gender & & & & 0.028 \\
\hline Male & $219(54.8 \%)$ & $66(46.5 \%)$ & $118(58.7 \%)$ & \\
\hline Female & 181 (45.3\%) & $76(53.5 \%)$ & $83(41.3 \%)$ & \\
\hline Age group & & & & 0.257 \\
\hline 18-40 years & 48 (12\%) & $11(15.9 \%)$ & $32(7.7 \%)$ & \\
\hline $41-60$ years & $120(30 \%)$ & 47 (30.8\%) & $62(33.1 \%)$ & \\
\hline$>60$ years & $232(58 \%)$ & $84(53.2 \%)$ & 107 (59.2\%) & \\
\hline Body mass index $\left(\mathrm{kg} / \mathrm{m}^{2}\right)^{*}(\mathrm{n}=324)$ & & & & 0.134 \\
\hline Under weight (Below 18.5) & $28(8.6 \%)$ & $11(9 \%)$ & $13(9 \%)$ & \\
\hline Healthy or normal (18.5-24.9) & $130(40 \%)$ & $48(39.3 \%)$ & $62(38.3 \%)$ & \\
\hline Overweight $(25-29.9)$ & 107 (33\%) & $34(27.9 \%)$ & $63(38.9 \%)$ & \\
\hline Obese (More than 30) & $59(18.2 \%)$ & $29(23.8 \%)$ & $24(14.8 \%)$ & \\
\hline Race & & & & 0.434 \\
\hline Malay & 207 (51.8\%) & 83 (58.9\%) & 101 (50.2\%) & \\
\hline Chinese & 135 (33.8\%) & $40(28.4 \%)$ & 72 (35.8\%) & \\
\hline Indian & 55 (13.8\%) & 17 (12.1\%) & 27 (13.4\%) & \\
\hline Others $^{b}$ & $3(0.75 \%)$ & $1(0.7 \%)$ & $1(0.5 \%)$ & \\
\hline \multicolumn{5}{|l|}{ Comorbidities } \\
\hline Diabetes & $260(65 \%)$ & 105 (73.9\%) & $118(68.7 \%)$ & 0.004 \\
\hline Hypertension & 360 (90\%) & 131 (92.3\%) & 177 (88.1) & 0.227 \\
\hline Hyperlipidemia & 76 (19\%) & 31 (21.8\%) & 33 (16.4\%) & 0.209 \\
\hline Ischemic heart disease & $94(23.5 \%)$ & 30 (21.1\%) & $53(26.4 \%)$ & 0.306 \\
\hline Congestive heart failure & $26(6.5 \%)$ & 7 (4.9\%) & 5 (2.5\%) & 0.246 \\
\hline Cerebrovascular accident & $16(4 \%)$ & $12(8.5 \%)$ & $10(5 \%)$ & 0.263 \\
\hline Hyperparathyroidism & $23(5.8 \%)$ & $4(2.8 \%)$ & $10(5 \%)$ & 0.412 \\
\hline Hypoparathyroidism & 17 (4.3\%) & $4(2.8 \%)$ & $2(1 \%)$ & 0.236 \\
\hline Hepatitis B & $22(5.5 \%)$ & $4(2.8 \%)$ & $1(0.5 \%)$ & 0.097 \\
\hline No. of comorbidities & & & & 0.036 \\
\hline 2 or less & 181 (45.3\%) & $53(37.3 \%)$ & 99 (49.3\%) & \\
\hline More than 2 & $219(54.8 \%)$ & $89(62.7)$ & $102(50.7 \%)$ & \\
\hline No. of medications patient was taking & & & & 0.914 \\
\hline Less than 5 & $4(1 \%)$ & $2(1.4 \%)$ & $2(1 \%)$ & \\
\hline 5 to 10 & 267 (68\%) & 95 (66.9\%) & $135(68.5 \%)$ & \\
\hline More than 10 & $124(31 \%)$ & 45 (31.7\%) & 60 (30.5\%) & \\
\hline \multicolumn{5}{|l|}{ No. of years on dialysis } \\
\hline 2 or less & 163 (40.8\%) & $58(40.8 \%)$ & 71 (35.3\%) & \\
\hline More than 2 & $237(59.2 \%)$ & $84(59.2 \%)$ & $130(64.7 \%)$ & \\
\hline Type of dialysis & & & & 0.228 \\
\hline Hemodialysis & 222 (55.5\%) & $81(57 \%)$ & $101(50.2 \%)$ & \\
\hline Peritoneal dialysis & $178(44.5 \%)$ & $61(43 \%)$ & 100 (49.8\%) & \\
\hline \multicolumn{5}{|l|}{ Type of access } \\
\hline Arterioventricular fistula (AVF) & 104 (26\%) & $24(17 \%)$ & $70(34.8 \%)$ & \\
\hline Central venous catheter (CVC) & $75(18.8 \%)$ & $32(27.7)$ & $21(10.4)$ & \\
\hline Tenchkoff catheter & 170 (42.5\%) & 57 (40.4\%) & 95 (47.3\%) & \\
\hline Multiple accesses ${ }^{c}$ & $51(12.8 \%)$ & 28 (19.9\%) & $15(7.5 \%)$ & \\
\hline Vital status & & & & $<0.001$ \\
\hline Alive & 268 (67\%) & $89(62.7 \%)$ & $179(89.1 \%)$ & \\
\hline Dead & 75 (18.8\%) & 53 (37.3) & 22 (10.9\%) & \\
\hline Status unknown & 57 (14.3\%) & & & \\
\hline History of HCAI & 174 (43.5\%) & & & \\
\hline
\end{tabular}

Bold values mean significant $\mathrm{p}$-values.

*Incomplete patient records.

${ }^{a}$ Chi-square test.

${ }^{b}$ Thai and Indonesian.

${ }^{c}$ More than one type of dialysis access used during renal replacement therapy, IQR, interquartile range.

found to be independent risk factors for death as a treatment outcome, while recurrent HCAIs (OR = 33; 95\%CI:4-282, $p$-value $=0.001)$, use of CVCs $(\mathrm{OR}=4.2 ; 95 \% \mathrm{CI}: 0.9-18.6$, $p$-value $=0.053)$ and low serum sodium levels $(\mathrm{OR}=3.9 ; 95 \%$ CI:0.9-15, $p$-value $=0.052$ ) were risk factors associated with treatment failure (Table 5). 


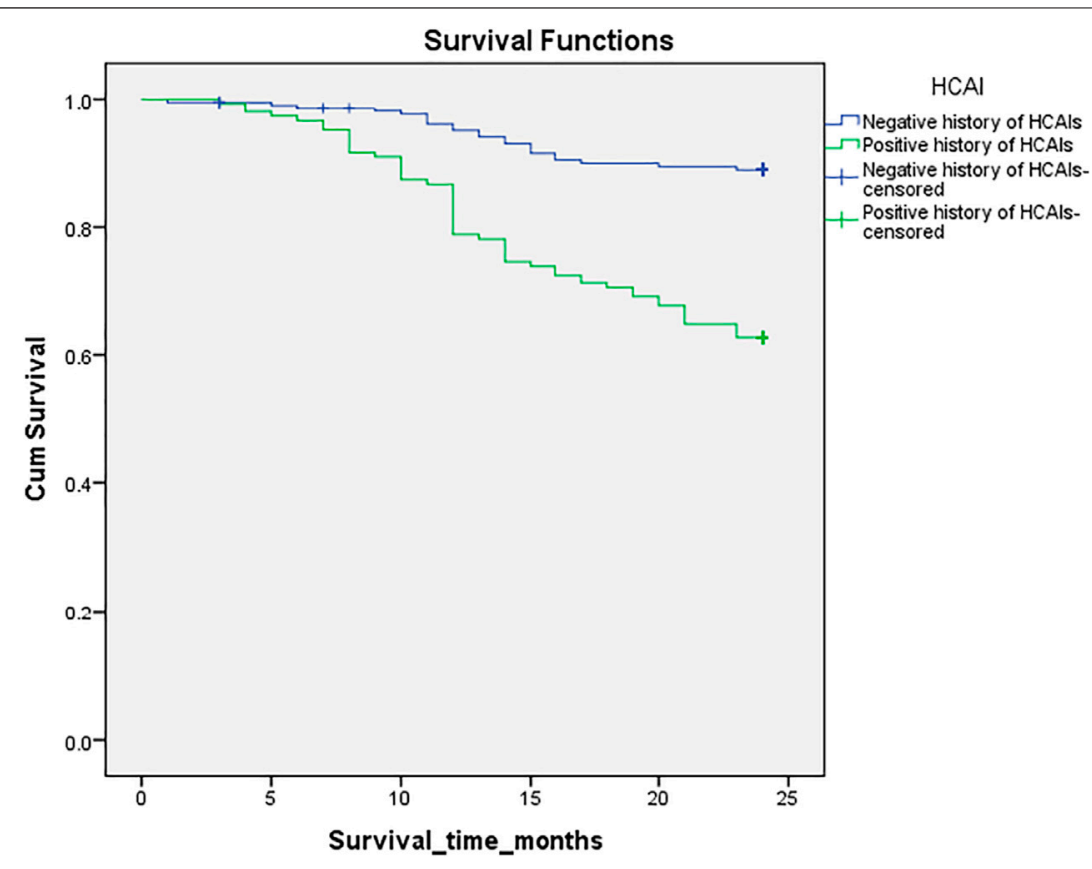

FIGURE 1 | Kaplan-Meier survival analysis in patients with and without healthcare associated infections. Cum survival; Cummulative survival.

\section{DISCUSSION}

The study reported a high prevalence $(43.5 \%)$ of HCAIs among ESRD disease patients undergoing renal RRT. Among the 174 patients with HCAIs, clinical cure (64.9\%) was the most frequent treatment outcome, followed by death $(21.3 \%)$ and treatment failure (9.8\%). Patients' characteristics such as advancing age, low serum sodium levels and low blood $\mathrm{Hb}$ concentration were associated with increased mortality in these patients. Furthermore, recurrent HCAIs, occurrence of CRBSI, use of CVCs, and low serum sodium levels were more likely to cause treatment failure in patients with HCAIs. Multivariate logistic regression showed advancing age, and low blood $\mathrm{Hb}$ concentration to be independent risk factors for death as a treatment outcome. Recurrent HCAIs, use of CVCs, and hyponatremia were risk factors associated with treatment failure.

Advancing age has shown to increase the chances of mortality by 1.1-folds. Moreover, within age groups, patients aged 18-40 and 41-60 years had significantly higher mean survival time (22.8 and 22.5 months respectively) than patients aged $>60$ years (20.7 months). Increased mortality is highly associated with poor functional status and aggregation of clinical comorbidities in elderly patients on RRT (Wright, 2015). According to United States Renal Data System (USRDS) registry, nearly $30 \%$ of all older adults ( $\geq 65$ years) on dialysis died in the year 2015 (Wachterman et al., 2019). Therefore, management of RRT related issues such as maintaining vascular access and infection complications, must be addressed with caution. Clinicians must incorporate screening and treatment strategies for various RRT associated complications in elderly patients, including infections, in their routine plan of care.
Low blood $\mathrm{Hb}$ concentration was likely to cause 10 -folds increase in mortality in the present study. Similarly, a higher mean survival time of 22.9 months was seen in patients with normal blood $\mathrm{Hb}$ concentration compared to mean survival time of 21.1 months in patients with lower blood $\mathrm{Hb}$. Similar results have been shown in the previous studies where higher achieved hemoglobin $(\mathrm{Hb})$ levels were associated with decreased mortality (Volkova and Arab, 2006; Bradbury et al., 2009). According to USRDS, longer the patient's Hb levels remain $<11 \mathrm{~g} / \mathrm{dl}$, more are the chances of death (Bradbury et al., 2009). The compromised kidney function and prevalence of malnutrition in ESRD patients on RRT, which is evidenced by reduced blood $\mathrm{Hb}$ and hypoalbuminemia, may lead to dysfunction of the immune system and therefore, increase the risk of infections induced mortality (Tang and Chen, 2016). Thus, the provision of nutritional support for patients on RRT is vital to help in improving the immune function and decrease infection related deaths. Moreover, adequate dosing and of epoetin alfa (EPO) is necessary to raise $\mathrm{Hb}$ concentration in these patients and in case of poor $\mathrm{Hb}$ response to EPO therapy, proper dosage adjustment should be performed by pharmacists and physicians.

Patients with recurrent HCAIs were strongly associated with increased occurrence of treatment failure by 33 -folds. Another study identified various factors associated with recurrent CRBSI in HD patients, including inappropriate duration of therapy and inappropriate catheter management, while appropriate antibiotic selection was not found to be associated with recurrent CRBSI (Zhang et al., 2019). Due to these recurrent infections, patients on RRT play a predominant role in the epidemics and outbreaks of antibiotic resistant pathogens, such as vancomycin-resistant enterococci (VRE) and vancomycin-resistant Staphylococcus 
TABLE 2 | Survival trends of study participants through Kaplan-Meier survival analysis.

\begin{tabular}{|c|c|c|c|c|c|c|}
\hline Variables & $\begin{array}{l}\text { Total no. } \\
\text { of participants, } \\
(\mathrm{N}=342)\end{array}$ & Time, months & Death, $n$ & $\begin{array}{l}\text { Mean survival } \\
\text { time, months } \\
\text { (SE) }\end{array}$ & $95 \% \mathrm{Cl}$ & $p$-value \\
\hline HCAls & & & & & & $<0.001$ \\
\hline Postive history & 142 & 24 months & 53 & $19.9(0.52)$ & $18.8-20.9$ & \\
\hline Negative history & 201 & 24 months & 22 & $22.7(0.27)$ & $22.1-23.2$ & \\
\hline Gender & & & & & & 0.303 \\
\hline Male & 184 & 24 months & 44 & $21.1(0.41)$ & 20.3-21.9 & \\
\hline Female & 159 & 24 months & 31 & $21.9(0.37)$ & $21-22.1$ & \\
\hline Age group & & & & & & 0.001 \\
\hline $18-40$ years & 43 & 24 months & 4 & $22.8(0.56)$ & 21.7-23.9 & \\
\hline $41-60$ years & 109 & 24 months & 15 & $22.5(0.39)$ & $21.7-23.3$ & \\
\hline$>60$ years & 191 & 24 months & 56 & $20.7(0.425)$ & $19.8-21.5$ & \\
\hline Body mass index $(\mathrm{kg} / \mathrm{m} 2)^{\star}(\mathrm{n}=284)$ & & & & & & 0.282 \\
\hline Under weight (Below 18.5) & 24 & 24 months & 8 & $19.7(1.2)$ & $17.2-22.3$ & \\
\hline Healthy or normal (18.5-24.9) & 110 & 24 months & 27 & $21.6(0.4)$ & $20.7-22.6$ & \\
\hline Overweight (25-29.9) & 97 & 24 months & 17 & $22(0.4)$ & $21.1-22.9$ & \\
\hline Obese (More than 30) & 53 & 24 months & 14 & $20.9(0.7)$ & $19.3-22.4$ & \\
\hline Race & & & & & & 0.357 \\
\hline Malay & 184 & 24 months & 41 & $21.6(0.36)$ & 20.9-22.3 & \\
\hline Chinese & 112 & 24 months & 26 & $21.2(0.53)$ & $20.1-22.2$ & \\
\hline Indian & 44 & 24 months & 7 & $22.2(0.66)$ & $20.9-23.5$ & \\
\hline Others & 2 & 24 months & 1 & $14(7)$ & $0.1-27.8$ & \\
\hline Type of dialysis & & & & & & 0.319 \\
\hline Hemodialysis & 182 & 24 months & 35 & $21.5(0.39)$ & $20.7-22.3$ & \\
\hline Peritoneal dialysis & 161 & 24 months & 40 & $21.5(0.39)$ & $20.7-22.3$ & \\
\hline No. of years on dialysis & & & & & & 0.657 \\
\hline 2 or less years & 129 & 24 months & 30 & $21.3(0.49)$ & 20.3-22.2 & \\
\hline$>2$ years & 214 & 24 months & 45 & $21.7(0.33)$ & $21-22.3$ & \\
\hline \multicolumn{7}{|l|}{ Type of vascular access } \\
\hline Arterioventricular fistula (AVF) & 94 & 24 months & 12 & $22(0.54)$ & $21-23.1$ & \\
\hline Central venous catheter (CVC) & 53 & 24 months & 15 & $20.6(0.79)$ & $19-22.1$ & \\
\hline Tenchkoff catheter & 152 & 24 months & 39 & $21.4(0.41)$ & $20.6-22.2$ & \\
\hline Multiple accesses & 43 & 24 months & 9 & $21.9(0.68)$ & $20.5-23.2$ & \\
\hline No. of comorbidities & & & & & & 0.005 \\
\hline 1 or 2 & 152 & 24 months & 23 & $22.5(0.31)$ & $21.9-23.1$ & \\
\hline More than 2 & 191 & 24 months & 52 & $20.7(0.42)$ & $19.9-21.6$ & \\
\hline Diabetes & & & & & & 0.271 \\
\hline Yes & 223 & 24 months & 53 & $21.4(0.34)$ & $20.8-22.1$ & \\
\hline No & 120 & 24 months & 22 & $21.6(0.48)$ & $20.7-22.6$ & \\
\hline Hypertension & & & & & & 0.296 \\
\hline Yes & 308 & 24 months & 70 & $21.4(0.29)$ & 20.89-22 & \\
\hline No & 35 & 24 months & 5 & $22.2(0.80$ & 20.6-23.8 & \\
\hline Hyperlipidemia & & & & & & 0.193 \\
\hline Yes & 64 & 24 months & 18 & $21(0.64)$ & $19.7-22.2$ & \\
\hline No & 279 & 24 months & 57 & $21.6(0.31)$ & 21.22 .2 & \\
\hline Ischemic heart disease & & & & & & 0.489 \\
\hline Yes & 83 & 24 months & 20 & $20.8(0.67)$ & $19.5-22.1$ & \\
\hline No & 260 & 24 months & 55 & $21.7(0.3)$ & $21.1-22.3$ & \\
\hline Cerebrovascular accident & & & & & & 0.607 \\
\hline Yes & 22 & 24 months & 4 & $22.5(0.77)$ & $20.9-24$ & \\
\hline No & 321 & 24 months & 71 & $21.4(0.29)$ & $20.9-22$ & \\
\hline No. of medicicines patient was taking ${ }^{\star}(n=339)$ & & & & & & 0.035 \\
\hline Less than 5 & 4 & 24 months & 3 & $18(2.3)$ & $13.3-22.6$ & \\
\hline 5 to 10 & 230 & 24 months & 51 & $21.4(0.34)$ & $20.8-22.1$ & \\
\hline More than 10 & 105 & 24 months & 21 & $21.7(0.49)$ & $20.7-22.6$ & \\
\hline TWBCs & & & & & & $<0.001$ \\
\hline High & 110 & 24 months & 41 & $19.4(0.61)$ & $18.2-20.6$ & \\
\hline Normal & 220 & 24 months & 27 & $22.7(0.25)$ & 22.2-23.2 & \\
\hline Low & 13 & 24 months & 7 & $18.6(1.7)$ & $15.2-22$ & \\
\hline Hemoglobin & & & & & & 0.004 \\
\hline Normal & 70 & 24 months & 6 & $22.9(0.45)$ & $22-23.8$ & \\
\hline Low & 273 & 24 months & 69 & $21.1(0.32)$ & $\begin{array}{l}20.5-21.8 \\
\text { hued on follo }\end{array}$ & page) \\
\hline
\end{tabular}


TABLE 2 | (Continued) Survival trends of study participants through Kaplan-Meier survival analysis.

\begin{tabular}{|c|c|c|c|c|c|c|}
\hline Variables & $\begin{array}{l}\text { Total no. } \\
\text { of participants, } \\
(\mathrm{N}=342)\end{array}$ & Time, months & Death, $n$ & $\begin{array}{l}\text { Mean survival } \\
\text { time, months } \\
\text { (SE) }\end{array}$ & $95 \% \mathrm{Cl}$ & $p$-value \\
\hline $\mathrm{RBCs}^{*}(n=330)$ & & & & & & 0.054 \\
\hline Normal & 60 & 24 months & 7 & $22.6(0.54)$ & $21.5-23.7$ & \\
\hline Low & 270 & 24 months & 63 & $21.4(0.31)$ & $20.8-22$ & \\
\hline Urea* $(n=341)$ & & & & & & 0.060 \\
\hline High & 299 & 24 months & 71 & $21.4(0.3)$ & $20.8-21.9$ & \\
\hline Normal & 42 & 24 months & 4 & $22.6(0.6)$ & $21.3-23.9$ & \\
\hline Sodium & & & & & & 0.001 \\
\hline Normal & 228 & 24 months & 38 & $22.2(0.3)$ & $21.6-22.8$ & \\
\hline Low & 115 & 24 months & 37 & $20.2(0.55)$ & $19.1-21.3$ & \\
\hline Total protein* $(n=312)$ & & & & & & 0.001 \\
\hline Normal & 178 & 24 months & 1 & $23.5(0.45)$ & $22.6-24.4$ & \\
\hline Low & 134 & 24 months & 74 & $21.2(0.31)$ & $20.6-21.8$ & \\
\hline Random blood sugar* $(n=284)$ & & & & & & $<0.001$ \\
\hline High & 106 & 24 months & 33 & $20.6(0.56)$ & $19.5-21.7$ & \\
\hline Normal & 178 & 24 months & 24 & $22.4(0.31)$ & $21.8-23.1$ & \\
\hline HbA1c range* $(n=310)$ & & & & & & 0.196 \\
\hline High & 169 & 24 months & 42 & $21.3(0.4)$ & $20.6-22.1$ & \\
\hline Normal & 141 & 24 months & 26 & $21.7(0.4)$ & $20.8-22.5$ & \\
\hline C-reactive protein & & & & & & $<0.001$ \\
\hline High & 212 & 24 months & 66 & $20.5(0.4)$ & $19.7-21.3$ & \\
\hline Normal & 127 & 24 months & 9 & $23.2(0.28)$ & $22.6-23.8$ & \\
\hline
\end{tabular}

*Incomplete patient records.

HCAl, healthcare associated infection; TWBCs, total white blood cells; RBCs, red blood cells. Bold values mean significant $\mathrm{p}$-values.

TABLE 3 | Univariate and multivariate Cox regression analysis of study participants' predictors for survival.

regression analysis

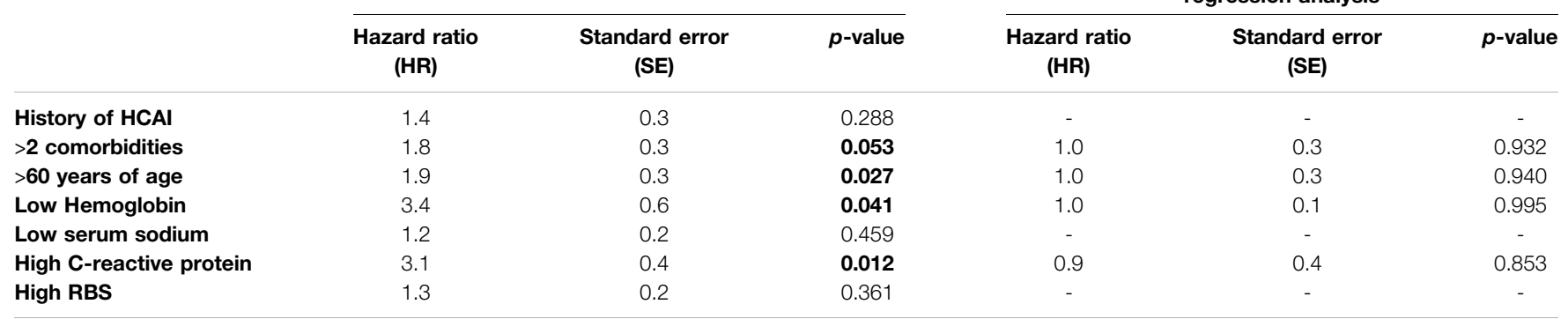

HCAl, healthcare associated infection; RBS, random blood sugar. Bold values mean significant p-values.

aureus (Zacharioudakis et al., 2015). Moreover, first reports on isolation of these resistant pathogens involved patients on RRT (Zacharioudakis et al., 2015). Antimicrobial stewardship programs and infection control and prevention strategies should be implemented to discourage inappropriate use and promote rationale use of antibiotics particularly in dialysis population.

CRBSIs was the most common HCAI found in this study and use of CVCs was associated with 4.2-folds increase in treatment failure as compared to clinical cure. CRBSIs cause considerable increase in morbidity, mortality and healthcare costs (Sahli et al., 2017). Being part of the normal flora, S. aureus is the most common pathogen identified in these infections (Sahli et al., 2017), and due to the high prevalence of vancomycin-resistant $S$. aureus in dialysis patients (Zacharioudakis et al., 2015), the chances of treatment failure are considerably high. Empirical therapy with antibiotics against methicillin sensitive S. aureus and methicillin resistant $S$. aureus should be considered when there is risk of catheter related infection. Furthermore, microbiological profiles of the patients should be carefully monitored to choose optimum empirical therapy.

In 24 months survival analysis, a significantly higher mean survival time of 22.7 months was seen in patients without HCAIs than of 19.9 months in patients with HCAIs. Infection is one major cause of mortality and increases the length of hospitalization in ESRD patients (McDonald et al., 2014). A study conducted in United States showed that 9.6 percent of all the deaths incident dialysis patients were caused by infections (Collins et al., 2015). Moreover, mortality due to septicemia and sepsis is significantly higher for chronic dialysis patients than in general public (Sarnak and Jaber, 2000). Efforts should be made to develop strict infection control policies and prevention strategies to reduce the risk of HCAIs. The exposure of ESRD 
TABLE 4 | Demographics and clinical variables associated with treatment outcomes of healthcare associated infections.

\begin{tabular}{|c|c|c|c|c|c|c|}
\hline & \multirow[b]{2}{*}{$\begin{array}{l}\text { Patients with } \\
\text { HCAls }(n=174)\end{array}$} & \multicolumn{4}{|c|}{ Treatment outcomes } & \multirow[b]{2}{*}{$p$-value* } \\
\hline & & $\begin{array}{c}\text { Clinical cure } \\
(n=113)\end{array}$ & $\begin{array}{c}\text { Death } \\
(n=37)\end{array}$ & $\begin{array}{l}\text { Treatment failure } \\
\qquad(n=17)\end{array}$ & $\begin{array}{l}\text { Defaulted or } \\
\text { transferred out } \\
(n=7)\end{array}$ & \\
\hline Median age in years (IQR) & $62(16)$ & $61(17)$ & $66(16)$ & $60(20)$ & $73(27)$ & 0.001 \\
\hline \multicolumn{7}{|l|}{ Gender } \\
\hline Male & 86 (49.4\%) & $53(46.9 \%)$ & $19(51.4 \%)$ & $10(58.8 \%)$ & $4(57.1 \%)$ & \\
\hline $18-40$ years & $16(9.2 \%)$ & $12(10.6 \%)$ & $2(5.4 \%)$ & $2(11.8 \%)$ & $0(0.0 \%)$ & \\
\hline $41-60$ years & $51(29.3 \%)$ & $33.6(30 \%)$ & $6(16.2 \%)$ & $6(35.3 \%)$ & $2(28.6 \%)$ & \\
\hline$>60$ years & $107(61.5 \%)$ & $63(55.8 \%)$ & $29(78.4 \%)$ & 9 (52.9\%) & $5(71.4 \%)$ & \\
\hline Body mass index $\left(\mathrm{kg} / \mathrm{m}^{2}\right)^{\star}(n=145)$ & & & & & & 0.690 \\
\hline Under weight (Below 18.5) & $12(8.3 \%)$ & $8(8.6 \%)$ & $4(12.5 \%)$ & $0(0.0 \%)$ & $0(0.0 \%)$ & \\
\hline Healthy or normal $(18.5-24.9)$ & $61(42.1 \%)$ & 37 (39.8\%) & $15(46.9 \%)$ & $6(42.9 \%)$ & $3(60 \%)$ & \\
\hline Overweight (25-29.9) & 39 (26.9\%) & $26(28 \%)$ & $5(15.6 \%)$ & $6(42.9 \%)$ & $1(20 \%)$ & \\
\hline Hyperlipidemia & $38(21.8 \%)$ & $21(18.6 \%)$ & $10(27 \%)$ & $5(29.4 \%)$ & $1(14.3 \%)$ & 0.553 \\
\hline Ischemic heart disease & $36(20.68 \%)$ & $24(21.2 \%)$ & 7 (18.9\%) & $2(11.8 \%)$ & $3(42.9)$ & 0.390 \\
\hline Congestive heart failure & $15(8.62 \%)$ & $13(11.5 \%)$ & $1(2.7 \%)$ & $1(5.9 \%)$ & $0(0.0 \%)$ & 0.301 \\
\hline Anemia & $13(7.47 \%)$ & $9(8 \%)$ & $2(5.4 \%)$ & $1(5.9 \%)$ & $1(14.3 \%)$ & 0.849 \\
\hline Infections recurrence & 66 (37.9\%) & 34 (30.1\%) & $14(37.8 \%)$ & $16(94.1 \%)$ & $2(28.6 \%)$ & $<0.001$ \\
\hline No. of comorbidities & & & & & & 0.612 \\
\hline 2 or less & 67 (38.5\%) & 45 (39.8\%) & $15(40.5 \%)$ & $4(23.5 \%)$ & 3 (42.9\%) & \\
\hline More than 2 & 107 (61.5\%) & $68(60.2 \%)$ & $22(59.5 \%)$ & $13(76.5 \%)$ & $4(57.1 \%)$ & \\
\hline No. of medications patient was taking & & & & & & 0.090 \\
\hline Less than 5 & $2(1.2 \%)$ & $0(0.0 \%)$ & $2(5.4 \%)$ & $0(0.0 \%)$ & $0(0.0 \%)$ & \\
\hline 5 to 10 & $119(68.8 \%)$ & 74 (66.5\%) & $28(75.7 \%)$ & $11(68.8 \%)$ & $6(85.7 \%)$ & \\
\hline More than 10 & $52(30.1 \%)$ & 34.5 (31\%) & 7 (18.9\%) & $5(31.3 \%)$ & $1(14.3)$ & \\
\hline No. of years on dialysis & & & & & & 0.382 \\
\hline Tenchkoff catheter & 69 (39.65\%) & $44(39.3 \%)$ & 19 (51.4\%) & $2(11.8 \%)$ & $4(57.1 \%)$ & \\
\hline Multiple accesses ${ }^{\mathrm{a}}$ & $31(17.81 \%)$ & 24 (21.4\%) & $4(10.8 \%)$ & $3(17.6 \%)$ & $0(0.0 \%)$ & \\
\hline \multicolumn{7}{|l|}{ Type of HCAl infection } \\
\hline CRBSI & 64 (36.8\%) & 40 (35.4\%) & $9(24.3 \%)$ & $13(76.5 \%)$ & $2(28.6 \%)$ & 0.003 \\
\hline Peritonitis & 45 (25.8\%) & 29 (25.7\%) & $12(32.4 \%)$ & $1(5.9 \%)$ & $3(42.9 \%)$ & 0.143 \\
\hline Pneumonia & 37 (21.2\%) & 23 (20.4\%) & $10(27 \%)$ & $3(17.6 \%)$ & $0(0.0 \%)$ & 0.418 \\
\hline Bacteremia & $23(13.2 \%)$ & $13(11.5 \%)$ & $6(16.2 \%)$ & $4(23.5 \%)$ & $0(0.0 \%)$ & 0.359 \\
\hline Exit site infection & 19 (10.9\%) & $13(11.5 \%)$ & $2(5.4 \%)$ & $3(17.6 \%)$ & $1(14.3 \%)$ & 0.558 \\
\hline UTI & $6(3.4 \%)$ & $2(1.8 \%)$ & $3(8.1 \%)$ & $1(5.9 \%)$ & $0(0.0 \%)$ & 0.270 \\
\hline TWBCs & & & & & & 0.117 \\
\hline Normal & 83 (47.7\%) & 50 (44.2\%) & $19(51.4 \%)$ & $10(58.8 \%)$ & $3(42.9 \%)$ & \\
\hline High & 82 (47.1\%) & 60 (53.1\%) & $13(35.1 \%)$ & $6(35.3 \%)$ & $4(57.1 \%)$ & \\
\hline Low & 9 (5.2\%) & $3(2.7 \%)$ & 5 (13.5\%) & $1(5.9 \%)$ & $0(0.0 \%)$ & \\
\hline Hemoglobin & & & & & & $<0.001$ \\
\hline Normal & $24(13.8 \%)$ & 18 (15.9\%) & 1 (2.7\%) & 4 (23.5\%) & 2 (28.6\%) & \\
\hline Low & $150(86.2 \%)$ & 95 (84.1\%) & $36(97.1 \%)$ & 13 (76.5\%) & 5 (71.4\%) & \\
\hline Urea & & & & & & 0.048 \\
\hline High & 162 (93.6\%) & 104 (91.7\%) & 36 (97.3\%) & 17 (100\%) & 5 (71.4\%) & \\
\hline Normal & $11(6.4 \%)$ & 9 (8.3\%) & 1 (2.7\%) & 0 (0.0\%) & 2 (28.6\%) & \\
\hline Sodium & & & & & & 0.011 \\
\hline Normal & 95 (54.6\%) & 72 (63.7\%) & 17 (45.9\%) & 5 (29.4\%) & 2 (28.6\%) & \\
\hline Low & 79 (45.4\%) & 41 (36.3\%) & 20 (54.1\%) & 12 (70.6\%) & $\begin{array}{c}5(71.4 \%) \\
\text { (Continued on fo }\end{array}$ & g page) \\
\hline
\end{tabular}


TABLE 4 | (Continued) Demographics and clinical variables associated with treatment outcomes of healthcare associated infections.

\begin{tabular}{|c|c|c|c|c|c|c|}
\hline & \multirow[b]{2}{*}{$\begin{array}{l}\text { Patients with } \\
\text { HCAls }(n=174)\end{array}$} & \multicolumn{4}{|c|}{ Treatment outcomes } & \multirow[b]{2}{*}{$p$-value* } \\
\hline & & $\begin{array}{l}\text { Clinical cure } \\
(n=113)\end{array}$ & $\begin{array}{l}\text { Death } \\
(n=37)\end{array}$ & $\begin{array}{l}\text { Treatment failure } \\
\qquad(n=17)\end{array}$ & $\begin{array}{l}\text { Defaulted or } \\
\text { transferred out } \\
(n=7)\end{array}$ & \\
\hline HbA1c range & & & & & & 0.213 \\
\hline High & 91 (56.5\%) & 59 (56.2\%) & 17 (50\%) & 12 (80\%) & 3 (42.9\%) & \\
\hline Normal & $70(43.5 \%)$ & 46 (43.8\%) & 17 (50\%) & $3(20 \%)$ & $4(57.1 \%)$ & \\
\hline Albumin & & & & & & 0.119 \\
\hline Normal & 18 (10.3\%) & $16(14.2 \%)$ & $0(0.0 \%)$ & $2(11.8 \%)$ & 1 (14.3\%) & \\
\hline Low & 156 (89.7\%) & 97 (85.8\%) & 37 (100\%) & 15 (88.2\%) & $6(85.7 \%)$ & \\
\hline Random blood sugar & & & & & & 0.569 \\
\hline High & 75 (57.7\%) & 46 (54.1\%) & $18(66.7 \%)$ & $8(61.5 \%)$ & $2(40 \%)$ & \\
\hline Normal & 55 (42.3\%) & 39 (45.9\%) & $9(33.3 \%)$ & 5 (38.5\%) & $3(60 \%)$ & \\
\hline
\end{tabular}

${ }^{*}$ Chi square test.

${ }^{a}$ More than one type of dialysis access used during renal replacement therapy.

IQR, interquartile range; CRBSI, catheter related blood stream infection, UTI: urinary tract infection; TWBCs, total white blood cells; HbA1c, hemoglobin A1c. Bold values mean significant p-values.

TABLE 5 | Multinomial logistic regression for risk factors associated with unsuccessful treatment outcomes.

\begin{tabular}{|c|c|c|c|c|}
\hline & \multicolumn{2}{|c|}{$\begin{array}{c}\text { Univariate multinomial logistic } \\
\text { regression }\end{array}$} & \multicolumn{2}{|c|}{$\begin{array}{c}\text { Multivariate multinomial logistic } \\
\text { regression }\end{array}$} \\
\hline & \multicolumn{2}{|c|}{$\begin{array}{c}\text { Odds ratio [95\% } \\
\text { CI (significance; } p \text {-value)] }\end{array}$} & \multicolumn{2}{|c|}{$\begin{array}{c}\text { Odds ratio [95\% } \\
\text { Cl (significance; } p \text {-value)] }\end{array}$} \\
\hline & Death versus cure & Treatment failure vs cure & Death versus cure & Treatment failure vs cure \\
\hline Age & $1.06[1.02-1.1(0.001)]$ & 0.99 [0.95-1 (0.887)] & $1.06[1.02-1.1(0.001)]$ & $0.97[0.9-1(0.329)]$ \\
\hline Recurrent HCAls & $1.4[0.6-3(0.382)]$ & 37 [4.7-291 (0.001)] & 1.6 [0.6-3.9 (0.289)] & 33 [4-282 (0.001)] \\
\hline CRBSI & $0.5[0.2-1.3(0.216)]$ & 5.9 [1.8-19.4 (0.003)] & 0.9 [0.3-2.7 (0.913)] & 2.9 [0.6-12.6 (0.156)] \\
\hline \multicolumn{5}{|l|}{ Type of dialysis } \\
\hline Hemodialysis & 0.7 [0.3-1.4 (0.347)] & 5.5 [1.2-25 (0.027)] & $0.4[0.1-1.2(0.130)]$ & $2.6[0.3-18.7(0.321)]$ \\
\hline Peritoneal dialysis & Ref & Ref & Ref & Ref \\
\hline \multicolumn{5}{|c|}{ Type of vascular access } \\
\hline AVF & $0.8[0.3-2.4(0.820)]$ & & & \\
\hline CVC & 1 [0.4-2.4 (0.980)] & $8.8[2.8-27(<0.001)]$ & 0.9 [0.2-3.4 (0.913)] & $4.2[0.9-18.6(0.053)]$ \\
\hline Tenchkoff catheter & $1.6[0.7-3.4(0.200)]$ & $0.2[0.04-0.9(0.042)]$ & $1.8[0.7-4.4(0.182)]$ & $0.2[0.03-1(0.054)]$ \\
\hline Multiple accesses & $0.4[0.1-1.3(0.160)]$ & $0.7[0.2-2.9(0.722)]$ & - & - \\
\hline \multicolumn{5}{|l|}{ Hemoglobin } \\
\hline Normal & $0.1[0.01-1.1(0.066)]$ & $1.6[0.4-5.5(0.439)]$ & - & - \\
\hline Low & 6.8 [0.8-52 (0.066)] & $0.6[0.1-2.1(0.439)]$ & 9.8 [1.1-86 (0.039)] & $0.8[0.1-4.2(0.809)]$ \\
\hline \multicolumn{5}{|l|}{ Urea } \\
\hline High & 2.7 [0.3-22.9 (0.345)] & - & - & - \\
\hline Normal & $0.3[0.04-2.9(0.345)]$ & - & - & - \\
\hline \multicolumn{5}{|l|}{ Sodium } \\
\hline Normal & 0.4 [0.2-1 (0.059)] & $0.2[0.07-0.7(0.011)]$ & - & - \\
\hline Low & 2 [0.9-4.3 (0.059)] & $4.2[1.3-12.8(0.011)]$ & $1.6[0.7-3.7(0.240)]$ & 3.9 [0.9-15 (0.052)] \\
\hline
\end{tabular}

HCAls, healthcare associated infections; CRBSI, catheter related blood stream infections; AVF, Arterioventricular fistula; CVC, central venous catheter.

patients to hospitals should be minimized to prevent these infections and in turn reduce mortality.

The survival analysis showed that patients with 2 or less comorbidities have shown a comparatively higher mean survival time (22.5 months) than patients with more than 2 comorbidities (20.7 months). Similar results were seen in patients with normal blood sugar levels (22.4 months) compared to patients with higher blood sugar levels (20.6 months). Several studies have reported that better glycemic control is associated with longer survival in patients on RRT, while poor glycemic control increases mortality due to infections (Shurraw et al., 2011; Ricks et al., 2012). Hence, efficient management of glycemic levels can help to reduce the occurrence of HCAIs and improve overall survival.

Hyponatremia has shown to decrease mean survival time in patients on RRT and was also found to cause increase occurrence of treatment failure. Waikar et al. demonstrated a constant connection between hyponatremia and increased mortality on dialysis, and this enhanced mortality is caused partly due to infectious complications (Waikar et al., 2011). Similarly, hyponatremia is correlated with greater risk of infectionrelated hospitalizations (Mandai et al., 2013). A study suggested that high concentration of serum sodium improve protective action against pathogens by promoting $\mathrm{CD} 4^{+}$cells 
differentiation into T-helper $17\left(\mathrm{~T}_{\mathrm{h}} 17\right)$ cells, while hyponatremia inhibits $\mathrm{T}_{\mathrm{h}} 17$ cells (Mandai et al., 2013).

To the best of our knowledge, this is the first study conducted on this topic, however, there were few limitations in our study. Although it was a multicenter study, but the collection of data from only two hospitals limits generalizability of results. To reduce the effect of this limitation to a minimum level, sufficient sample size was used in this study. Secondly, being a retrospective study, only the data present in the patients' medical records were collected. However, patients record at the hospitals were completed with great care and organization. Additionally, all the laboratory tests were performed using standardized protocols in these hospitals, hence it is unlikely that any event of HCAI remained undiagnosed. Moreover, the authors did their best to make sure that the data was collected with great caution, and all ambiguities were resolved by the help of hospital staff and coinvestigators from the hospitals. The third limitation of this study is related to the search of patients. All patients were searched using ICD codes for ESRD, hence there is a chance of skipping any patient that fulfilled the criteria for inclusion but was diagnosed with different ICD code. However, random sampling technique was used in this study to overcome this problem. Finally, the modified version of Friedman's definition of HCAIs was used in this study. It is possible that using any other definition might affect the results.

\section{CONCLUSION}

The high burden of HCAIs is profound challenge faced by patients on RRT, which not only effects the treatment outcomes but also contribute substantially to the poor survival among these patients. Infection control policies and prevention strategies should be implemented to overcome these risk factors. Recurrent infections and use of antibiotics are considerably high among the patients on RRT due to frequent and complex surgical procedures and various comorbid conditions. Therefore, appropriate selection, duration, and use of antibiotics is pivotal to not only improve patients' clinical outcomes but also to decrease the prevalence antibiotic resistant pathogens. Patient contact with hospitals and other healthcare settings should be kept to minimum to reduce the risk of infections, and hence improving clinical outcomes and survival among ESRD patients. Future prospective studies and randomized control trials should provide a narrow focus on antibiotic therapy,

\section{REFERENCES}

Albuquerque, S. E., Cavalcante, R. S., Ponce, D., and Fortaleza, C. M. (2014). Epidemiology of Healthcare-Associated Infections Among Patients from a Hemodialysis Unit in southeastern Brazil. Braz. J. Infect. Dis. 18 (3), 327-330. doi:10.1016/j.bjid.2013.10.001

Bradbury, B. D., Danese, M. D., Gleeson, M., and Critchlow, C. W. (2009). Effect of Epoetin Alfa Dose Changes on Hemoglobin and Mortality in Hemodialysis Patients with Hemoglobin Levels Persistently below 11 g/dL. Cjasn 4 (3), 630-637. doi:10.2215/cjn.03580708 treatment outcomes and their associated risk factors, which will further clarify the burden and effect of these contributing factors.

\section{DATA AVAILABILITY STATEMENT}

The raw data supporting the conclusions of this article will be made available by the authors, without undue reservation.

\section{ETHICS STATEMENT}

The studies involving human participants were reviewed and approved by 1) University Malaya Medical Research Ethics Committee (MREC ID NO: 2019320-7245) 2) National Malaysian Research Registry (NMRR-19-777-47089). Written informed consent for participation was not required for this study in accordance with the national legislation and the institutional requirements. Written informed consent was not obtained from the individual(s) for the publication of any potentially identifiable images or data included in this article.

\section{AUTHOR CONTRIBUTION}

SA and RA have planned the study. SA conducted the survey and both SA and RA drafted the first version of the manuscript. PL, SL, and RZA verified the validity of statistical analysis and critically reviewed the manuscript. All authors have been involved in all stages of the manuscript. Finally, all authors read and approved the submission of final manuscript.

\section{ACKNOWLEDGMENTS}

The authors would like to acknowledge the Centre for Higher Degrees by Research (CHDR) of Taylor's University for providing fellowship for SA. The authors wish to pay gratitude to RA, who worked as a co-investigator during the study. The authors would also like to thank the staff members of University of Malaya Medical Centre and Serdang hospital as well as members of Clinical Research Committee (CRC) for providing their support in data retrieval phase. This publication paper is funded by Taylor's University.

Çilli, A., Sayıner, A., Çelenk, B., Şakar Coşkun, A., Kılınç, O., Hazar, A., et al. (2018). Antibiotic Treatment Outcomes in Community-Acquired Pneumonia. Turk J. Med. Sci. 48 (4), 730-736. doi:10.3906/sag-1709-144

Collins, A. J., Foley, R. N., Gilbertson, D. T., and Chen, S.-C. (2015). United States Renal Data System Public Health Surveillance of Chronic Kidney Disease and End-Stage Renal Disease. Kidney Int. supplements 5 (1), 2-7. doi:10.1038/ kisup. 2015.2

Donlon, S., Redmond, A., McCann, M., and Einarsdottir, H. (2011). Prevention of Infection in Patients with Chronic Kidney Disease Part III: Surveillance and Auditing in a Renal Care Environment. J. Ren. Care 37 (3), 167-173. doi:10.1111/j.1755-6686.2011.00251.x 
Etikan, I., Abubakar, S., and Alkassim, R. (2017). The Kaplan Meier Estimate in Survival Analysis. Biom Biostat Int. J. 5 (2), 55-59. doi:10.15406/ bbij.2017.05.00128

World Health Organization (2012). The Evolving Threat of Antimicrobial Resistance : Options for Action. Available from: https://apps.who.int/iris/ handle/10665/44812 (cited December 7, 2019).

Friedman, N. D., Kaye, K. S., Stout, J. E., McGarry, S. A., Trivette, S. L., Briggs, J. P., et al. (2002). Health Care-Associated Bloodstream Infections in Adults: A Reason to Change the Accepted Definition of Community-Acquired Infections. Ann. Intern. Med. 137 (10), 791-797. doi:10.7326/0003-4819-137-10200211190-00007

Ghazali, A. L. Y., Goh, B. L., Wong, H. S., Liu, W. J., Lee, M. L., Phillip, N. J., et al. (2016). 24th Report of the Malaysian Dialysis and Transpant Registry. Available at: https://www.msn.org.my/msn/Doc/PublicDoc_PB/Publication/mdtr2016/ All\%20Chapters.pdf (Accessed December 15, 2019).

Gupta, N., Cannon, M., and Srinivasan, A. (2013). National Agenda for Prevention of Healthcare-Associated Infections in Dialysis Centers. Seminars In Dialysis. Hoboken, NJ: Wiley Online Library.

Mandai, S., Kuwahara, M., Kasagi, Y., Kusaka, K., Tanaka, T., Shikuma, S., et al. (2013). Lower Serum Sodium Level Predicts Higher Risk of Infection-Related Hospitalization in Maintenance Hemodialysis Patients: an Observational Cohort Study. BMC Nephrol. 14, 276. doi:10.1186/1471-2369-14-276

McDonald, H. I., Thomas, S. L., and Nitsch, D. (2014). Chronic Kidney Disease as a Risk Factor for Acute Community-Acquired Infections in High-Income Countries: a Systematic Review. BMJ Open 4 (4), e004100. doi:10.1136/ bmjopen-2013-004100

Raosoft (2004). Sample Size Calculator 2004. Available from: http://www.raosoft. com/samplesize.html (cited April 20, 2019).

Research Randomizer (1997). Urbaniak GC. Available from: https://www. randomizer.org/. (cited April 3, 2019).

Ricks, J., Molnar, M. Z., Kovesdy, C. P., Shah, A., Nissenson, A. R., Williams, M., et al. (2012). Glycemic Control and Cardiovascular Mortality in Hemodialysis Patients with Diabetes: a 6-year Cohort Study. Diabetes 61 (3), 708-715. doi:10.2337/db11-1015

Sahli, F., Feidjel, R., and Laalaoui, R. (2017). Hemodialysis Catheter-Related Infection: Rates, Risk Factors and Pathogens. J. Infect. Public Health 10 (4), 403-408. doi:10.1016/j.jiph.2016.06.008

Sarnak, M. J., and Jaber, B. L. (2000). Mortality Caused by Sepsis in Patients with End-Stage Renal Disease Compared with the General Population. Kidney Int. 58 (4), 1758-1764. doi:10.1111/j.1523-1755.2000.00337.x

Shurraw, S., Hemmelgarn, B., Lin, M., Majumdar, S. R., Klarenbach, S., Manns, B., et al. (2011). Association between Glycemic Control and Adverse Outcomes in People with Diabetes Mellitus and Chronic Kidney Disease. Arch. Intern. Med. 171 (21), 1920-1927. doi:10.1001/archinternmed.2011.537

Tang, L., and Chen, J. (2016). Economic Impact of Nosocomial Infection in Hemodialysis Patients. Acta Med. Mediterranea 32 (SpecialIssue1), 617-621.

Thomas, B., Wulf, S., Bikbov, B., Perico, N., Cortinovis, M., Courville de Vaccaro, K., et al. (2015). Maintenance Dialysis throughout the World in Years 1990 and 2010. Jasn 26 (11), 2621-2633. doi:10.1681/ asn.2014101017
Volkova, N., and Arab, L. (2006). Evidence-based Systematic Literature Review of Hemoglobin/hematocrit and All-Cause Mortality in Dialysis Patients. Am. J. kidney Dis. 47 (1), 24-36. doi:10.1053/j.ajkd.2005.09.007

Wachterman, M. W., O’Hare, A. M., Rahman, O.-K., Lorenz, K. A., Marcantonio, E. R., Alicante, G. K., et al. (2019). One-year Mortality after Dialysis Initiation Among Older Adults. JAMA Intern. Med. 179 (7), 987-990. doi:10.1001/ jamainternmed.2019.0125

Waikar, S. S., Curhan, G. C., and Brunelli, S. M. (2011). Mortality Associated with Low Serum Sodium Concentration in Maintenance Hemodialysis. Am. J. Med. 124 (1), 77-84. doi:10.1016/j.amjmed.2010.07.029

Wang, Z., and Hoy, W. E. (2013). Diabetes and Lifetime Risk of ESRD in High-Risk Remote-Dwelling Australian Aboriginal People: A 20-Year Cohort Study. Am. J. Kidney Dis. 62 (4), 845-846. doi:10.1053/j.ajkd.2013.05.021

Wen, Y., Zhang, Z., Li, X., Xia, D., Ma, J., Dong, Y., et al. (2018). Treatment Outcomes and Factors Affecting Unsuccessful Outcome Among New Pulmonary Smear Positive and Negative Tuberculosis Patients in Anqing, China: a Retrospective Study. BMC Infect. Dis. 18 (1), 104. doi:10.1186/s12879-018-3019-7

Wright, S. (2015). Online Curricula: Geriatric Nephrology. Washington, D.C.: Nephrology ASo. Available from: https://www.asn-online.org/education/ distancelearning/curricula/geriatrics/ (Accessed June 7, 2019).

Zacharioudakis, I. M., Zervou, F. N., Ziakas, P. D., Rice, L. B., and Mylonakis, E. (2015). Vancomycin-resistant Enterococci Colonization Among Dialysis Patients: A Meta-Analysis of Prevalence, Risk Factors, and Significance. Am. J. Kidney Dis. 65 (1), 88-97. doi:10.1053/j.ajkd.2014.05.016

Zelenitsky, S. A., Harding, G. K., Sun, S., Ubhi, K., and Ariano, R. E. (2003). Treatment and Outcome of Pseudomonas aeruginosa Bacteraemia: an Antibiotic Pharmacodynamic Analysis. J. Antimicrob. Chemother. 52 (4), 668-674. doi:10.1093/jac/dkg403

Zhang, H. H., Cortés-Penfield, N. W., Mandayam, S., Niu, J., Atmar, R. L., Wu, E., et al. (2019). Dialysis Catheter-Related Bloodstream Infections in Patients Receiving Hemodialysis on an Emergency-Only Basis: A Retrospective Cohort Analysis. Clin. Infect. Dis. 68 (6), 1011-1016. doi:10.1093/cid/ciy555

Conflict of Interest: The authors declare that the research was conducted in the absence of any commercial or financial relationships that could be construed as a potential conflict of interest.

Publisher's Note: All claims expressed in this article are solely those of the authors and do not necessarily represent those of their affiliated organizations, or those of the publisher, the editors and the reviewers. Any product that may be evaluated in this article, or claim that may be made by its manufacturer, is not guaranteed or endorsed by the publisher.

Copyright (c) 2021 Abbasi, Aftab, Lai, Lim and Zainol Abidin. This is an open-access article distributed under the terms of the Creative Commons Attribution License (CC $B Y$ ). The use, distribution or reproduction in other forums is permitted, provided the original author(s) and the copyright owner(s) are credited and that the original publication in this journal is cited, in accordance with accepted academic practice. No use, distribution or reproduction is permitted which does not comply with these terms. 